Article

\title{
Understanding the Sustainable Development of L2 Chinese Teachers in New Zealand: A Case Study of Teaching Assistants' Motivational Engagement in Teaching Chinese as a Foreign Language
}

\author{
Peijian Paul Sun (D)
}

check for

updates

Citation: Sun, P.P. Understanding the Sustainable Development of L2 Chinese Teachers in New Zealand: A Case Study of Teaching Assistants' Motivational Engagement in Teaching Chinese as a Foreign Language. Sustainability 2021, 13, 5521. https://doi.org/10.3390/su13105521

Academic Editors: Lawrence Zhang and Vincent Greenier

Received: 24 April 2021

Accepted: 12 May 2021

Published: 14 May 2021

Publisher's Note: MDPI stays neutral with regard to jurisdictional claims in published maps and institutional affiliations.

Copyright: (C) 2021 by the author. Licensee MDPI, Basel, Switzerland. This article is an open access article distributed under the terms and conditions of the Creative Commons Attribution (CC BY) license (https:// creativecommons.org/licenses/by/ $4.0 /)$.
Department of Linguistics, Zhejiang University, Hangzhou 310058, China; luapnus@zju.edu.cn

\begin{abstract}
Informed by the expectancy-value theory and the motivational factors influencing teaching model choices, this case study explored three Chinese-as-a-foreign-language teaching assistants' (L2 Chinese TAs') motivational engagement in teaching L2 Chinese as a sustainable and lifelong career in New Zealand. Each TA participated in three rounds of semi-structured interviews in the process of data collection. The findings revealed that (1) the TAs' expectancy was all student oriented, regardless of their different backgrounds; (2) the different values of L2 Chinese teaching contributed to the TAs' teaching performance and career choices; and (3) the impact of teaching self-efficacy on the TAs' profession retention was pivotal, but controversial, when taking their previous majors into account. Implications for the sustainable development of L2 Chinese teachers were discussed.
\end{abstract}

Keywords: teaching assistant; L2 Chinese teaching; motivational engagement; lifelong career; sustainable development

\section{Introduction}

Teacher motivation has been proven to be a prominent contributing factor to sustainable and lifelong classroom teaching. Teaching with or without motivation may result in different learning outcomes for students. Much research has suggested that teachers with high motivation may help students to reach higher levels of achievement [1]. Such a positive link between teacher motivation and student achievement, in turn, may strengthen teachers' motivation for teaching [2], serving as an impetus for teachers' ongoing and sustainable career development [3,4].

With the rising status of China, millions of teachers have been recruited for supporting Chinese-as-a-foreign-language (L2 Chinese) teaching in primary and secondary schools and in institutions of higher education worldwide. Among the various types of teachers, teaching assistants (TAs), as common fixtures at universities, are often employed to compensate for teacher shortage and attrition [5].

To date, increasing research has investigated in-service and pre-service teachers' motivation [1]. However, insufficient attention has been paid to this special group of university teaching fellows-namely, TAs. Given the fact that TAs have the potential to choose teaching as a lifelong career in the future, it is of great importance to investigate TAs' teaching motivation in order to better understand the factors contributing to TAs' sustainable development and career choices. As a result, suggestions in terms of how to better support the professional development of TAs could be offered for the retention of such a special group of teaching fellows.

In attempting to bridge the shortage of research on TAs' teaching motivations, and also to respond to the call for more research into L2 Chinese teachers, this study explored three L2 Chinese TAs' motivational engagement in L2 Chinese teaching at a university in New Zealand. Particularly, motivational factors influencing the TAs' L2 Chinese teaching as a 
sustainable career were examined. A multiple-case-study approach was adopted for this investigation through semi-structured interviews. More specifically, the expectancy-value theory [6,7] and the motivational factors influencing teaching (FIT) choice model [8] were adopted as theoretical and analytical lenses through which to comprehensively uncover the TAs' motivational reasons for L2 Chinese teaching, as well as the challenges and difficulties they encountered in such positions. This study not only serves as an initial attempt to uncover TAs' motivational engagement in teaching L2 Chinese as a career in an overseas context, but also aims to provide some practical insights into the sustainable development of L2 Chinese teachers. An overarching question guided the present study:

RQ: What motivational factors contributed to TAs' engagement in teaching L2 Chinese as a sustainable career?

\section{Literature Review and Theoretical Framework}

\subsection{Teacher Motivation}

Teacher motivation refers to teachers' intentions of entering the profession and their engagement in and commitment to the profession [9]. Within the teacher education literature, intrinsic, extrinsic, and altruistic motives have long been identified as three prominent reasons that teachers commit to the teaching profession.

Intrinsic motivation can be referred to as individuals' inherent satisfaction gained from performing an activity. Such satisfaction in teaching can stem from reasons such as "to educate people", "to impart knowledge and values", or "to advance a community or a whole nation" [9] (p. 161). It was suggested that intrinsically motivated teachers would endeavor to strengthen learners' intrinsic motivation in learning [10,11]. However, such motivation could be subject to social and cultural conditions and constraints [12,13]. Kilınç et al. [14], for example, found that science teachers in Turkey are less intrinsically motivated due to social dissuasion; that is, science and technology majors deserve better jobs in a science- and technology-driven economy.

Extrinsic motivation, in contrast, focuses on the benefits of teaching and other external rewards, rather than the satisfaction and enjoyment coming from teaching itself [12]. Researchers found that salary, vacations, job security, and job status are important extrinsic motivational factors attracting individuals to become teachers [8,15]. It was also found that job-related incentives, such as honorary awards and monetary rewards, might be detrimental to the school climate, because such incentives seem to divide teachers into winners and losers [16]. As a result, those teachers labeled as losers might gradually lose interest in teaching.

Altruistic motivation in teaching considers teaching to be a socially worthwhile profession, such as being a part of students' growth and development [17,18]. Much research has suggested that there is a strong connection between intrinsic and altruistic motivations. For example, it was found that teachers' desire to engage in the academic and personal development of students could be due to their intrinsic love of the students [19].

However, the distinction between intrinsic, extrinsic, and altruistic motivations can be obscure and imprecise due to the "overlapping categorizations of motivations" and "unclear or absent theoretical and analytical frameworks" [8,20,21] (p. 284). For instance, teachers' desire to work with their students can be regarded as either intrinsic or altruistic. Therefore, it is not satisfactory to merely adopt such a classification for the interpretation of teacher motivation.

\subsection{Theoretical Framework of Teaching Motivation}

The expectancy-value theory [6,7] and the motivational FIT choice model [8] are two important motivational frameworks developed for the interpretation of behavioral motivation. As a commonly cited theoretical framework, the expectancy-value theory was formed based on J. W. Atkinson's [6] concept of expectancy-value, which was proposed in order to understand how individuals' achievement motives, success expectancies, and incentive values influence their achievement behaviors. Following this concept, Eccles 
et al. [7] proposed an expectancy-value model in order to investigate how students' expectancies and values relate to their performance and choices in the domain of secondary mathematics. According to the theoretical model, success expectation and subjective task value are the major types of motivation that can directly predict individuals' academic choices and behaviors. To be more specific, success expectation refers to learners' beliefs about how well they will do in upcoming tasks, while subjective task value can be defined as the qualities of tasks and how such qualities influence learners' desire to complete the tasks, including attainment value, intrinsic value, utility value, and cost $[7,22]$.

The expectancy-value theory also resonates with many other motivational theories, including self-efficacy, self-determination, interest, and goal theories [23]. Self-efficacy theory, for example, centers on the role of the expectance of success, arguing that efficacy expectations or beliefs can determine individuals' behavioral outcomes [24]. Self-determination theory, in contrast, focuses on the extent to which individuals' behavior is self-motivated and self-determined, emphasizing the importance of individuals' innate needs and intrinsic motivation [25]. Additionally, many studies have examined motivation from the interest and goal perspectives. Research drawing on the interest theory pays close attention to the influence of individual interest (e.g., stable preference) and situational interest (e.g., transient emotion) on one's behavior [23]; whereas research based on the goal theory is interested in how goals can be transformed into actions, which in turn results in better performance and achievement of learners [26,27].

Extending the expectancy-value theory, Watt and Richardson [8] constructed a distinctive and comprehensive framework of motivation - the motivational FIT choice modelin order to explore factors that contribute to teachers' commitment to teaching as a career. Based on this model, the motivational FIT choice questionnaire was developed "to guide systematic investigation into the question of why people choose a teaching career" [28] (p. 31). Twelve motivation factors and six perception factors under four dimensions (i.e., task, value, self-perception, and fallback career) were confirmed through factor analyses [8]. Specifically, the task dimension is composed of task demand (e.g., expert career and high demand) and task return (e.g., social status, teacher morale, and salary), while the value dimension includes intrinsic value, personal utility value (e.g., job security, time for family, job transferability, and bludging), and social utility value (e.g., shaping the futures of children/adolescents, enhancing social equity, making social contributions, and working with children/adolescents). The self-perception dimension is proposed to measure individuals' perceptions of their teaching abilities, while fallback career is constructed to reflect "claims in the teacher education literature and the public media regarding teaching as fallback career" [8] (p. 174).

Drawing on Watt and Richardson's [8] motivational FIT choice model, a respectable number of studies have probed into teachers' motivations for teaching in different countries, including Turkey, China, Switzerland, Germany, and the USA [21]. These studies not only confirmed the validity of the model, but also found that teaching motivation can be multifaceted, context dependent, and even contradictory. For example, Torsney et al., [29] examined 216 pre-service teachers' intentions for future professional engagement in the USA. It was found that social utility value was the most positive predictor of professional engagement. Additionally, Kissau et al. [30] investigated 54 preservice teachers' motivation for becoming an L2 teacher and their commitment to the teaching profession in the USA. The results showed that these preservice teachers were motivated by their perceived social contribution, ability to shape students' futures, ability to teach, prior teaching and learning experiences, and love of the language. McLean et al. [31] longitudinally examined 265 undergraduate seniors' motivations for choosing teaching as a career in a teacher training program in the USA. The study suggested that intrinsic and altruistic motivations may contribute to lower burnout and higher career optimism, while extrinsic motivations may result in more burnout and lower career optimism. 


\subsection{Challenges and Difficulties of Teaching Abroad}

Teaching abroad can be highly challenging and overwhelming. One major difficulty of teaching abroad can be drastic changes in living, working, and teaching environments. Teachers not only have to adapt quickly to new living situations, but also must be ready to put out fires in culturally and pedagogically different classroom settings [32,33]. Specifically, teachers may experience cultural discomfort when teaching abroad for the first time due to different objective (e.g., clothes, food, music) and subjective (e.g., values, beliefs, and habits) cultures. Teachers may also encounter students with different characters and needs compared to students in their home country. As a result, expectations and values they once had may not fit with students in an overseas teaching context. For example, Ye and Edwards' [34] study found that due to the lack of understanding of students with learning difficulties, Chinese language teachers would regard these students as misbehaving, and tended to hold a negative attitude towards them. Ye and Edwards [34] also found that Chinese language teachers had problems understanding students' different accents and varieties of English in the UK, causing problems for their communication with students.

Although teachers worldwide have demonstrated a student-centered teaching orientation, they may still experience pedagogical challenges when teaching in a totally different country. For example, when there is a mismatch between teachers' and students' pedagogical beliefs, it may "cause frustration in students' learning" and "teachers' pedagogical practice" [35] (p. 75). Therefore, teachers should have the competence to pedagogically adjust themselves to various teaching contexts. In brief, teaching abroad can be culturally and pedagogically challenging, particularly for those who are teaching abroad for the first time [36].

\section{Methodology}

A multiple-case-study approach was adopted to examine different types of L2 Chinese TAs who were working at X University in New Zealand. Such an approach has the advantage of documenting the differences and the similarities between different cases [37]. This multiple-case study was conducted over a semester with three L2 Chinese TAs, in an attempt to obtain an in-depth understanding of the motivational factors contributing to TAs' engagement in teaching L2 Chinese as a sustainable career overseas.

\subsection{Research Context}

This multiple-case study was situated at X University in New Zealand. The university has well-established L2 programs. Such programs range from Diploma in Language Teaching to Ph.D. in Applied Linguistics. Each year, 100-200 students will register for the Chinese 100 course - a beginner-level course in Mandarin Chinese offered by the university. Four full-time faculty staff and four to six part-time TAs are responsible for teaching all of the Chinese language courses, covering the beginner, intermediate, and advanced levels. L2 Chinese TA recruitment is mainly subject to applicants' enrolment status, educational qualifications, employment experience, supervisors' approval, and interview performance.

\subsection{Participants}

The participants in this multiple-case study were three L2 Chinese TAs teaching beginner-level Mandarin to college students. To explore the similarities and differences between cases, purposive sampling was adopted for participant selection [38]. The three L2 Chinese TAs were selected because they were different in age, educational background, and working experience (see Table 1 for more details). Specifically, Wendy was a majorunrelated TA who had no previous L2 Chinese teaching experience before taking the L2 Chinese TA position. She finished her BA in English in China, and was now pursuing her MA in Translation Studies at X University. Sally was a major-switched TA with five years of L2 Chinese teaching experience before joining X University. She obtained her BA in Tourism and Management in China. However, Sally decided to commit herself to L2 Chinese education after four years of L2 Chinese teaching, and started her MA in Teaching 
Chinese to Speakers of Other Languages (TCSOL). She finished her MA with a one-year practicum in Vietnam. After graduation, she applied to the headquarters of the Confucius Institute, and was offered a three-contract position as an L2 Chinese TA in the university. Mindy was a major-consistent TA who had two years of overseas teaching experience prior to her L2 Chinese TA position at X University. Mindy obtained both her BA and MA in TCSOL from prestigious Chinese universities. She was now pursuing her second MA in Applied Linguistics and Teaching at the university. It should be noted that Wendy, Sally, and Mindy are all pseudonyms used to protect the participants' privacy when presenting the data gathered from the three participants.

Table 1. Case background.

\begin{tabular}{ccccc}
\hline Name & Sex & Age & Major & Background \\
\hline Wendy & Female & 28 & $\begin{array}{c}\text { Major-unrelated } \\
\text { TA }\end{array}$ & $\begin{array}{c}\text { BA in English; MA in Translation Studies; 3 } \\
\text { years of English (in China) and 1.5 years of } \\
\text { L2 Chinese teaching experience. }\end{array}$ \\
\hline Sally & Female & 33 & $\begin{array}{c}\text { Major-switched } \\
\text { TA }\end{array}$ & $\begin{array}{c}\text { BA in Tourism Management; MA in } \\
\text { Teaching Chinese to Speakers of Other } \\
\text { Languages (TCSOL); 6 years of L2 Chinese } \\
\text { teaching experience. }\end{array}$ \\
\hline Mindy & Female & 25 & $\begin{array}{c}\text { Major-consistent } \\
\text { TA }\end{array}$ & $\begin{array}{c}\text { BA and MA in TCSOL; MA in Language } \\
\text { Teaching; 3 years of L2 Chinese teaching } \\
\text { experience. }\end{array}$ \\
\hline
\end{tabular}

\subsection{Instruments}

Semi-structured interview protocols were developed, drawing on the expectancyvalue theory [6,7] and the motivational FIT choice model [8], in order to solicit TAs' beliefs and viewpoints concerning their motivational engagement in teaching L2 Chinese as a career in an overseas university setting. To enhance the trustworthiness of the instruments, two experts in the field of teacher education were invited to review the constructed semi-structured interview protocols. Following the experts' suggestions, the original oneshot interview was changed to three rounds over a semester. Such a change not only eases the lengthy procedure of the original interview, but also helps to profile the participants' opinions from a longitudinal perspective (see Appendix A for the sample interview protocol).

\subsection{Data Collection}

Prior to data collection, invitations were sent out to all of the L2 Chinese TAs for their possible participation based on an informed and voluntary basis. To maximize our understanding of TAs' motivational engagement in teaching L2 Chinese as a career, a diverse approach to case selection was adopted [39]. Specifically, three participants with distinctive educational backgrounds were selected for this multiple-case study. Each participant took part in three rounds of semi-structured interviews, taking place before, during, and after a semester-long course in beginner-level Chinese. The three semi-structured interviews focus largely, but not solely, on the participants' background information and previous teaching experiences, motivational factors towards L2 Chinese teaching, and L2 Chinese teaching challenges, respectively. All of the interviews were audiotaped and carried out in informal conversations between the participants and the first author.

\subsection{Data Analysis}

During data analysis, the participants were invited to check their respective interview transcripts for the sake of content accuracy. The qualitative interview data were analyzed through four levels of analysis: Firstly, the transcripts were carefully read and coded caseby-case. The reasons for L2 Chinese TAs' motivations towards teaching were highlighted. Sentences containing anticipatory words, such as "I hope", "I wish", "I want to", "I expect", 
"I must", "I should", and "I like" were particularly examined, based on the semantic content of each sentence.

Secondly, the coded transcripts were developed into coherent and rich case narratives. This not only makes the subsequent cross-case analysis available, but also allows readers to judge the transferability of the case interpretation. In order to enhance the internal validity and credibility of the research, the case narratives were also shared with the participants for member checking [40,41].

Thirdly, cross-case comparisons-a means of ensuring external validity-were carried out in order to reveal the commonalities and peculiarities of the cases [42,43]. To be more specific, the author examined each category based on the codes and narratives of all of the cases. Excerpts showing consistent and inconsistent results of the cases were highlighted for further analysis.

Lastly, and most importantly, the discovered motivational dimensions relating to the TAs' L2 Chinese teaching in an overseas university setting were interpreted and discussed, drawing on the expectancy-value theory and the motivational FIT choice model.

\section{Findings}

\subsection{Wendy's Case: Major-Unrelated TA}

As a major-unrelated TA, there were three major expectancies from Wendy's case. First and foremost, Wendy's expectancy was student-oriented. Wendy pointed out that she always "want[s] to inspire students' initiatives in learning Chinese. [She does] not want to do solo lecturing. [ ... ] [She] consistently try[s] [her] best to make students feel engaged, and to provoke their thinking" (Wendy, interview 1). Overall, Wendy "[hopes her] students will become more interested in Chinese through [her] being a bridge" (Wendy, interview 2).

Another expectancy that emerged from Wendy was training-oriented. As Wendy had no previous Chinese teaching experience, she found that relevant training could be helpful for TAs to be better prepared for L2 Chinese teaching in a university setting. As Wendy pointed out, "it is necessary to arrange training and workshops for novice TAs. It would be even better if we could observe our course coordinator's class. Just telling us what problems we may encounter and what facilities we can use may not be enough" (Wendy, interview 1).

The last expectancy that Wendy held was country-image-oriented. Wendy pointed out that students had stereotypes of China, such as filthy and poor. When it comes to such situations, Wendy would encourage students to visit China first before making such statements. "China is getting better. There are many cities like Beijing and Shanghai which are beautiful and magnificent" (Wendy, interview 1).

In terms of value, Wendy held a strong responsibility value. To better prepare herself for the L2 Chinese TA position, Wendy borrowed professional books for reference, observed other Chinese teachers' classes for ideas, and searched teaching materials online for organizing activities. She also regularly reflected on her teaching in order to improve her classroom practice. As Wendy pointed out, "it all depends on your self-discipline. You must reflect on your own practice and try to improve it for future teaching" (Wendy, interview 1). "Once you are on stage, you should have the responsibility and obligation to teach well" (Wendy, interview 2).

Apart from expectancies and values, Wendy's desire to become an L2 Chinese TA was motivated by her teachers and supported by her personality. Wendy mentioned that she used to be a shy girl back in primary school; hence, she did not have many opportunities to express herself. Her headteacher noticed the problem and helped her emerge from the shadows. Since then, she had "a positive impression of the teaching profession" (Wendy, interview 1). Wendy also found herself "easygoing and patient, which are essential personalities for being a teacher" (Wendy, interview 2).

In addition to her motivational engagement in L2 Chinese teaching, Wendy experienced some personal and contextual challenges in her professional practice, with negative influences on her motivations. Internally, Wendy was not confident in terms of answering 
students' grammar-related questions, given the fact that she was not from the Teaching Chinese to Speakers of Other Languages (TCSOL) major and had no previous L2 Chinese teaching experience. As Wendy said, "I need to enrich my professional knowledge, because sometimes I cannot answer students' questions" (Wendy, interview 3). Wendy also felt that her "English was not good enough" (Wendy, interview 1), her "knowledge of Chinese culture was insufficient compared with other TAs" (Wendy, interview 1), and her "ability to provide everyone with an equal opportunity of classroom participation" and "to teach the advanced level class" (Wendy, interview 2) needed to be strengthened.

Externally, Wendy found that there was too much to cover in each class. Consequently, she "barely [has] the time to carry out communicative activities in class" (Wendy, interview 2). Wendy also found that "training was insufficient, particularly for TAs without L2 Chinese teaching experience" (Wendy, interview 2); "there was no substantial discussion and self-reflection during the weekly meeting" (Wendy, interview 3); and "the two bulky textbooks were full of words and text without any colorful pictures" (Wendy, interview 3).

The above internal and external challenges constrained Wendy's intention and motivation towards L2 Chinese teaching as a profession. As Wendy pointed out, "I will teach Chinese for fun. I do not think there is a big chance for me to become a professional L2 Chinese teacher in the future" (Wendy, interview 1).

\subsection{Sally's Case: Major-Switched TA}

As a major-switched TA, three major expectancies were disclosed from Sally's case, including profession-oriented, student-oriented, and culture-oriented expectancies. Sally's L2 Chinese teaching experience made her realize what her true passion was. Although she graduated with a BA in Tourism and Management, Sally hoped that she could become a professional L2 Chinese teacher. Therefore, she started pursuing her MA in TCSOL.

"In the very beginning, I was not expecting myself to be a Chinese language teacher at all. I just felt that it was great fun to teach Chinese to foreigners. After three years of teaching, I started to think about how I could go further, and whether I should continue staying in this field. After taking all possible factors into consideration, I decided to continue, because I really love my job and I want to do it well."

\section{(Sally, interview 1)}

It can be suggested from the above that although Sally was a profession switcher, her passion and love for L2 Chinese teaching and her commitment to the career drove her to seek continuous learning in the field of TCSOL. In addition to her profession-oriented expectancy, Sally's teaching expectancy was student-oriented, with the hope of inspiring students' hunger for learning Chinese. For instance,

"I hope that my students could become more in love with Chinese learning because of my teaching. I hope that through my communication and interaction with them, and the activities that I organized for them, my students would have an in-depth understanding of China, have some progress in Chinese, and know more about Chinese culture. It is worth doing, even if there is just one student who benefits from my teaching."

\section{(Sally, interview 2)}

Apart from the profession-oriented and student-oriented expectancies, Sally was also culture-oriented. As she pointed out, a mutual cross-cultural understanding was important in dissolving conflicts. Sally further added that "I hope that students could understand more about Chinese culture. I hope that through their recognition of me as a Chinese teacher they could better understand the language and culture that I represent" (Sally, interview 1).

In terms of value, responsibility and intrinsic values were two major values that motivated Sally to be an L2 Chinese teacher. Sally claimed that teachers with a clear conscience would be responsible for their job. As a trilingual (Chinese, Korean, and English) person, she could have become an L2 Korean or English teacher. However, she decided to work as an L2 Chinese teacher. Sally explained as follows: 
"There is a difference between my Korean and my Chinese. I would regard Chinese as my first language, as I can use it without a problem. As for Korean, I can speak and listen, but I cannot write and read well, just like Chinese kids in New Zealand. It is irresponsible for me to teach Korean to students. I will lead them astray."(Sally, interview 1)

To a large extent, Sally was intrinsically motivated in tandem with the benefits of teaching. Sally constantly mentioned that she loved teaching and found it very fun. As she pointed out, "I love teaching. When students give me a card or a bar of chocolate to say thank you, I feel genuinely happy. They acknowledge your work. Although teaching all day can be physically tiring, you will get much fun out of interactions with your students" (Sally, interview 1).

In addition to expectancies and values, there are other motivational factors, such as self-efficacy and career belief, serving as an impetus for Sally to stay in the field of L2 Chinese education. For instance, Sally was quite confident about her L2 Chinese teaching competence. As Sally pointed out, "I think there are three essential criteria for being a good teacher. First, you should love your job. Second, you should not only have theoretical knowledge but also practical teaching skills. Third, you should have a strong ability of cross-cultural adaption. I think I have the full package" (Sally, interview 3). With respect to career belief, Sally did not think becoming an L2 Chinese teacher was a fallback career. As she pointed out, "being a Chinese teacher has been so far the most desirable occupation for me. It fits me well. I do not think I will consider other jobs" (Sally, interview 3).

Sally also experienced some personal and external challenges influencing her motivations towards working as a TA in New Zealand. Although Sally was a TA, she worked as "an after-class tutor and an assignment checker" (Sally, interview 1). Such a job duty made her feel demotivated. Nevertheless, Sally adjusted herself quickly to boost her motivation in L2 Chinese teaching. For example, she offered one-on-one tutoring, organized Chinese-related activities, and taught Chinese language courses at the Confucius Institute at X University.

Another challenge for Sally was the textbook adopted by X University. As she pointed out, "the textbook is not practical. There is too much detailed grammar. I do not think beginners need to know all these grammar points." (Sally, interview 2). Nonetheless, such a challenge motivated Sally to "come up with easier explanations to help students understand Chinese grammar, so that students' desire for learning L2 Chinese could be maintained" (Sally, interview 1).

The last challenge was her English proficiency. Sally found that when she was "trying to explain certain culture-related issues, she could not fully convey her ideas" (Sally, interview 1). Instead of feeling defeated, such a challenge motivated Sally to become more self-reflective in order to further strengthen her teaching competence.

\subsection{Mindy's Case: Major-Consistent TA}

As a major-consistent TA, there was only one main expectancy that emerged from Mindy: student-oriented expectancy. A major intention of Mindy's was to make students feel happy with Chinese learning. "I do not think it is a good idea to push students to learn something. You should make them feel happy while learning so that their motivation in learning can be sustained" (Mindy, interview 1). In addition, Mindy hoped that her students could become more open-minded through her class. As she pointed out, "when there is a culture-related discussion in class, there will be disagreements. Often, I will remind them that it is okay to hold on to their own viewpoints, but more importantly, they should learn to be inclusive and open-minded when it comes to difference" (Mindy, interview 3).

In terms of value, Mindy was mostly utility-driven. As she pointed out, "I am still young. I would like to try different things. Teaching Chinese is a channel for me to visit different countries" (Mindy, interview 1). Mindy's utility value was evidenced in her later comments. For example, "I am not that in favor of teaching Chinese. I just feel that I can travel to different countries through this job. I do not think I love this job, but I do not hate it either" (Mindy, interview 3). In addition to the utility, Mindy was occasionally motivated 
by her responsibility value. For instance, "sometimes when my students are dying to learn Chinese, I will have a strong sense of responsibility to teach it well" (Mindy, interview 2).

Apart from expectancies and values, Mindy's L2 Chinese teaching motivation was sustained by her professionalism and self-efficacy. In terms of professionalism, Mindy does not "think anyone can be an L2 Chinese teacher". In contrast, she believes that "majors do a better job than non-majors in Chinese language teaching, particularly when it comes to explaining grammar points" (Mindy, interview 3). With respect to self-efficacy, Mindy pointed out that "[she] majored in L2 Chinese teaching both for [her] BA and MA, so [she is] quite confident about [her] knowledge of and ability in Chinese language teaching" (Mindy, interview 3).

Although Mindy did not experience any serious challenges, due to her consistent educational training, she encountered some trivial ones in the process of L2 Chinese teaching. As Mindy pointed out, "it is not a challenge but rather unhappy moments. For example, when you ask students questions, no one bothers" (Mindy, interview 2). Mindy also found that "teachers can be like jugglers who should know many tricks to entertain their audience. They should have the ability to incorporate fun stuff into teaching. This can be difficult sometimes" (Mindy, interview 2). However, Mindy was neither motivated nor demotivated by such concerns, as she pointed out that "I just feel that I have been teaching Chinese for so long, it is no longer challenging to me anymore" (Mindy, interview 3).

\section{Discussions}

This study examined L2 Chinese TAs' motivational engagement in teaching L2 Chinese as a sustainable career in an overseas context, with its theoretical and analytical perspective underpinned by the expectancy-value theory and the motivational FIT choice model. An overview of the results of the cross-case analysis of the study can be found in the following Table 2 .

Table 2. Cross-case comparison.

\begin{tabular}{ccccc}
\hline Name & Expectancy & Value & Other Motivations & Challenges \\
\hline Wendy & $\begin{array}{c}\text { Student-oriented; } \\
\text { Training-oriented; } \\
\text { Country image }\end{array}$ & Responsibility & $\begin{array}{c}\text { Teachers; } \\
\text { Personality }\end{array}$ & $\begin{array}{c}\text { Various } \\
\text { internal and } \\
\text { external } \\
\text { challenges }\end{array}$ \\
\hline \multirow{2}{*}{ Sally } & $\begin{array}{c}\text { Profession-oriented; } \\
\text { Student-oriented; } \\
\text { Culture-oriented }\end{array}$ & $\begin{array}{c}\text { Responsibility; } \\
\text { Intrinsic }\end{array}$ & $\begin{array}{c}\text { Teaching self-efficacy; } \\
\text { Career beliefs }\end{array}$ & $\begin{array}{c}\text { Some personal } \\
\text { and external } \\
\text { challenges }\end{array}$ \\
\hline Mindy & Student-oriented & Utility & $\begin{array}{c}\text { Professionalism; } \\
\text { Teaching self-efficacy }\end{array}$ & No challenges \\
\hline
\end{tabular}

The findings from the expectancy perspective in this study, to some extent, reflected the teaching philosophy shift from teacher-dominant to student-centered teaching in foreign language education [44], given that the three TAs were all student-oriented (see Table 2). The TAs all suggested that teachers should foster students' interest in learning Chinese, rather than imparting knowledge to students through lecturing. Such findings also resonated with altruistic motivations, such as caring for students' growth and development $[45,46]$. Despite the similarities, an interesting difference revealed from the data was that Mindy, as a major-consistent TA, had the least number of expectancies serving as motivations for her professional sustainability, in comparison with either Wendy (a major-unrelated TA) or Sally (a major-switched TA).

One possible explanation could be the TAs' different ages and majors. Sally was the oldest TA, with relatively longer teaching experience. She also switched her major from a BA in Tourism Management to an MA in TCSOL. The above facts suggest that Sally may have a clearer vision of her professional path compared to the other two TAs. In terms of Wendy, neither her BA nor MA was in TCSOL. Therefore, it was not surprising to find 
that Wendy did not consider the L2 Chinese teaching profession as her priority, and there was no profession-oriented expectancy exuded from her. Mindy, in contrast, had both her BA and her MA in TCSOL. Interestingly, her expectancy was not profession-oriented either. This may be explained by the fact that young adults are more open to job mobility rather than finding a lifelong career $[47,48]$. Despite the TAs' different expectancies, the findings of this study lent evidence to the expectancy-value theory that expectations could influence individuals' performance and choice. Specifically, this study suggested that L2 Chinese TAs' student-oriented expectancies played a significant role in sustaining their engagement and persistence in L2 Chinese teaching as a career.

The findings from the value perspective in this study showed that L2 Chinese TAs were driven by different values, including responsibility (attainment), intrinsic, and utility (transferability) values (see Table 2). The value difference among the TAs may be caused by their different ages and lengths of teaching. Specifically, Mindy was the youngest among the three, and had relatively less teaching experience, while Sally was the oldest, and had the most teaching experience. As a result, teachers with more expertise and experience in teaching might form stronger teacher responsibility [49]. Despite the different values, the findings still corroborated the expectancy-value theory and the motivational FIT choice model, suggesting that different values - such as attainment value, intrinsic value, utility value, and job transferability - could influence individuals entering the field of teaching.

Aside from expectancies and values, other motivational factors contributing to the three TAs' L2 Chinese teaching as a sustainable career included role model and personality for Wendy, teaching self-efficacy and career belief (non-fallback career) for Sally, and teaching self-efficacy and professionalism for Mindy. Specifically, it could be inferred from the study that the consistency of TAs' previous majors might contribute to their L2 Chinese teaching self-efficacy. TAs without majors in TCSOL seemed to be less confident in L2 Chinese teaching compared to TAs who majored in TCSOL. As a result, the less confident TAs experienced more challenges while teaching, which in turn weakened their motivation to become teachers. Although teaching self-efficacy has been suggested to be pivotal for teachers' engagement in teaching, it may not always contribute to teachers' professional retention. Taking the major-consistent TA Mindy, for example, her strong teaching self-efficacy left her with no challenge in teaching, which in turn caused her passion for becoming a lifelong teacher to wane.

Last, but not least, the findings of this study suggested that the challenges that the three TAs encountered could to some extent be subject to their previous educational backgrounds. Specifically, Wendy-a major-unrelated TA-experienced the most challenges, while Mindy - a major-consistent TA - had the least. It is understandable that teachers with consistent relevant educational backgrounds may be more confident in the face of difficulties in teaching. For example, Shaukat et al.'s [16] (p. 73) study revealed that "teachers with sufficient educational qualification and professional training demonstrated more efficacious behavior".

\section{Conclusions}

This case study has shed light on motivational factors concerning TAs' engagement in teaching L2 Chinese as a sustainable career in an overseas context. Specifically, the findings revealed that: (1) the TAs' expectancy was all student-oriented, regardless of their different backgrounds; (2) the different values of L2 Chinese teaching contributed to the TAs' teaching performance and career choices; and (3) the impact of teaching self-efficacy on the TAs' profession retention was pivotal, but controversial, when taking their previous majors into account.

To enhance TAs' engagement in teaching L2 Chinese as a sustainable career, universities and teacher educators may take the following aspects into consideration: Firstly, due to the fact that student-oriented expectancy is common among TAs, universities and teacher educators may consider organizing group activities in order to further strengthen studentTA rapport. The strengthened bond between students and TAs, in turn, may enhance TAs' 
expectancy to choose L2 Chinese teaching as their sustainable and lifelong career. Secondly, universities and teacher educators should not only learn how to utilize TAs' current values in order to sustain their engagement in teaching as a career, but should also learn how to strengthen their intrinsic value in order to support their lifelong professional development. As suggested, values such as job transferability may not be sufficient to sustain teachers' willingness to undertake lifelong teaching [48], but rather, intrinsic values/motivations are the primary reasons for teachers' dedication to and sustainability in their profession $[21,50]$. Thirdly, given that self-efficacy is not only highly predictive of future behaviors [51,52], but also negatively correlated with teachers' stress and burnout [53,54], universities and teacher educators should therefore pay close attention to TAs' teaching self-efficacy by taking their previous educational backgrounds into account. For instance, more professional training on teaching may be more helpful for major-unrelated TAs while more career guidance and support may be more beneficial to major-consistent TAs for their sustainable development as teachers [55].

Without exception, there were limitations to this study. First, our research context was limited to New Zealand, with a small sample size, which makes it difficult for the findings to be generalized to other contexts. Future research may consider exploring the expectancy-value theory and the motivational FIT choice model in other contexts with similar participants for the sake of corroboration. Secondly, the data in our study are single-sourced, which may weaken the significance of our findings. Future research may consider adopting other qualitative methods, such as reflection diaries and focus groups, for the sake of cross-validation.

Funding: This research was supported by the Fundamental Research Funds for the Central Universities in China.

Institutional Review Board Statement: The study was conducted according to the guidelines ofthe Declaration of Helsinki, and approved by the Human Participants Ethics Committee of THE UNIVERSITY OF AUCKLAND $(014726,2014)$.

Informed Consent Statement: Informed consent was obtained from all subjects involved in the study. Written informed consent has been obtained from the participants to publish this paper.

Data Availability Statement: The data presented in this study are available on request from the corresponding author. The data are not publicly available due to ethical considerations.

Conflicts of Interest: The author declares no conflict of interest.

\section{Appendix A}

Interview Protocol Sample

Interview One

- Where are you from? What is your educational background?

- Why did you choose to become a Chinese language teaching assistant?

- Are there any significant others who have influenced your choice of teaching Chinese language? If so, who are they?

- Do you like being a teaching assistant?

- Have you had any teaching experience before? If so, does it influence your current Chinese teaching?

- How would you evaluate your teaching performance at this university?

Interview Two

- $\quad$ Are you satisfied with the pay for working as a teaching assistant?

- Do you find any benefits of teaching Chinese language?

- What are your goals in teaching? How do you try to achieve them in your classroom?

- In addition to improving students' Chinese language, do you have other expectations of your students?

- Do you agree with the statement that everyone can teach Chinese language? 
- What does it take to be a good Chinese teacher or teaching assistant?

- Do you have moments when you doubt your teaching ability?

Interview Three

- Have you received any professional training on Chinese teaching before you worked here? If so, in what way does it help your current teaching?

- What difficulties did you face when you first taught here? How did you cope with them?

- Have you experienced any change in your Chinese teaching over time? If so, what are the reasons behind the change?

- What challenges do you face now in your teaching? How do you try to deal with them?

- Have you received any support and guidance in your teaching (e.g., from the program and their schools)? If so, in what way did they help you?

- How do you see your students, colleagues, and leaders at your university? How do they perceive you as a Chinese teacher?

- Can you think of any critical incidents that have influenced your professional lives in your school? How do you think of them now?

- Will you choose Chinese language teaching as a sustainable career?

- Is there anything I did not ask, but that you want to share with me?

\section{References}

1. Han, J.; Yin, H. Teacher motivation: Definition, research development and implications for teachers. Cogent Educ. 2016, 3, 1217819. [CrossRef]

2. Chetty, R.; Friedman, J.N.; Hilger, N.; Saez, E.; Schanzenbach, D.W.; Yagan, D. How does your kindergarten classroom affect your earnings? Evidence from project STAR. Q. J. Econ. 2011, 126, 1593-1660. [CrossRef]

3. Guarino, C.M.; Santibañez, L.; Daley, G.A. Teacher recruitment and retention: A review of the recent empirical literature. Rev. Educ. Res. 2006, 76, 173-208. [CrossRef]

4. Oke, A.O.; Ajagbe, M.A.; Ogbari, M.E.; Adeyeye, J.O. Teacher retention and attrition: A review of the literature. Mediterr. J. Soc. Sci. 2016, 7, 371-378. [CrossRef]

5. Muzaka, V. The niche of graduate teaching assistants (GTAs): Perceptions and reflections. Teach. High. Educ. 2009, 14, 1-12. [CrossRef]

6. Atkinson, E.S. An investigation into the relationship between teacher motivation and pupil motivation. Educ. Psychol. 2000, 20, 45-57. [CrossRef]

7. Eccles, J.; Adler, T.F.; Futterman, R.; Goff, S.B.; Kaczala, C.M.; Meece, J.L.; Midgley, C. Expectancies, values, and academic behaviors. In Achievement and Achievement Motives: Psychological and Sociological Approaches; Spence, J.T., Ed.; W. H. Freeman: San Francisco, CA, USA, 1983; pp. 75-146.

8. Watt, H.M.G.; Richardson, P.W. Motivational factors influencing teaching as a career choice: Development and validation of the FIT-choice scale. J. Exp. Educ. 2007, 75, 167-202. [CrossRef]

9. Dörnyei, Z.; Ushioda, E. Teaching and Researching Motivation, 2nd ed.; Pearson: Harlow, UK, 2011.

10. Atkinson, J.W. Motivational determinants of risk-taking behavior. Psychol. Rev. 1957, 64, 359-372. [CrossRef]

11. Lam, S.; Cheng, R.W.; Ma, W.Y.K. Teacher and student intrinsic motivation in project-based learning. Instr. Sci. 2009, 37, 565-578. [CrossRef]

12. Ryan, R.M.; Deci, E.L. Intrinsic and extrinsic motivations: Classic definitions and new directions. Contemp. Educ. Psychol. 2000, 25, 54-67. [CrossRef]

13. Ryan, R.M.; Deci, E.L. Intrinsic and extrinsic motivation from a self-determination theory perspective: Definitions, theory, practices, and future directions. Contemp. Educ. Psychol. 2020, 61, 101860. [CrossRef]

14. Kılıç, A.; Watt, H.M.G.; Richardson, P.W. Factors influencing teaching choice in turkey. Asia Pac. J. Teach. Educ. 2012, 40, 199. [CrossRef]

15. Wang, D.; Zhang, L.J. Sustainability as a goal in teaching workforce retention: Exploring the role of teacher identity construction in preservice teachers' job motivation. Sustainability 2021, 13, 2698. [CrossRef]

16. Lauermann, F. Teacher responsibility from the teacher's perspective. Int. J. Educ. Res. 2014, 65, 75-89. [CrossRef]

17. Bakar, A.R.; Mohamed, S.; Suhid, A.; Hamzah, R. So you want to be a teacher: What are your reasons? Int. Educ. Stud. 2014, 7, 155. [CrossRef]

18. Bastick, T. Why teacher trainees choose the teaching profession: Comparing trainees in metropolitan and developing countries. Int. Rev. Educ. 2000, 46, 343-349. [CrossRef]

19. Nieto, S. What Keeps Teachers Going? Teachers College Press: New York, NY, USA, 2003. 
20. Richardson, P.W.; Watt, H.M.G. Factors influencing teaching choice: Why do future teachers choose the career? In International Handbook of Teacher Education; Loughran, J., Hamilton, M.L., Eds.; Springer: Singapore, 2016; Volume 2, pp. 275-304. [CrossRef]

21. Watt, H.M.G.; Richardson, P.W. An introduction to teaching motivations in different countries: Comparisons using the FIT-choice scale. Asia Pac. J. Teach. Educ. 2012, 40, 185. [CrossRef]

22. Wigfield, A.; Eccles, J.S. Expectancy-value theory of achievement motivation. Contemp. Educ. Psychol. 2000, 25, 68-81. [CrossRef]

23. Eccles, J.S.; Wigfield, A. Motivational beliefs, values, and goals. Annu. Rev. Psychol. 2002, 53, 109-132. [CrossRef]

24. Bandura, A. Self-Efficacy: The Exercise of Control; Freeman: New York, NY, USA, 1997.

25. Deci, E.L.; Ryan, R.M. Intrinsic Motivation and Self-Determination in Human Behavior; Plenum: New York, NY, USA, 1985.

26. Butler, R. Teachers' achievement goal orientations and associations with teachers' help seeking: Examination of a novel approach to teacher motivation. J. Educ. Psychol. 2007, 99, 241-252. [CrossRef]

27. Janke, S.; Bardach, L.; Oczlon, S.; Lüftenegger, M. Enhancing feasibility when measuring teachers' motivation: A brief scale for teachers' achievement goal orientations. Teach. Teach. Educ. 2019, 83, 1-11. [CrossRef]

28. Richardson, P.W.; Watt, H.M.G. Who chooses teaching and why? Profiling characteristics and motivations across Australian universities. Asia Pac. J. Teach. Educ. 2006, 34, 27-56. [CrossRef]

29. Torsney, B.M.; Lombardi, D.; Ponnock, A. The role of values in pre-service teachers' intentions for professional engagement. Educ. Psychol. 2019, 39, 19-37. [CrossRef]

30. Kissau, S.; Davin, K.; Wang, C. Aspiring world language teachers: Their influences, perceptions, and commitment to teaching. Teach. Teach. Educ. 2019, 78, 174-182. [CrossRef]

31. McLean, L.; Taylor, M.; Jimenez, M. Career choice motivations in teacher training as predictors of burnout and career optimism in the first year of teaching. Teach. Teach. Educ. 2019, 85, 204. [CrossRef]

32. Cross, S.; Dunn, A. "I Didn't Know of a Better Way to Prepare to Teach": A Case Study of Paired Student Teaching Abroad. Teach. Educ. Q. 2016, 43, 71-90.

33. Devillar, R.A.; Jiang, B. From student teaching abroad to teaching in the U.S. classroom: Effects of global experiences on local instructional practice. Teach. Educ. Q. 2012, 3, 7-24.

34. Ye, W.; Edwards, V. Confucius institute teachers in the UK: Motivation, challenges, and transformative learning. Race Ethn. Educ. 2018, 21, 843-857. [CrossRef]

35. Yang, J. Understanding Chinese language teachers' beliefs about themselves and their students in an English context. System 2019, 80, 73-82. [CrossRef]

36. Halicioglu, M.L. Challenges facing teachers new to working in schools overseas. J. Res. Int. Educ. 2015, 14, 242-257. [CrossRef]

37. Baxter, P.; Jack, S. Qualitative case study methodology: Study design and implementation for novice researchers. Qual. Rep. Vol. 2008, 13, 544-559. [CrossRef]

38. Patton, M.Q. Qualitative Research and Evaluation Methods, 3rd ed.; Sage: Thousand Oaks, CA, USA, 2002.

39. Gerring, J.; Cojocaru, L. Selecting cases for intensive analysis: A diversity of goals and methods. Sociol. Methods Res. 2016, 45, 392-423. [CrossRef]

40. Creswell, J.W. Research Design: Qualitative, Quantitative, and Mixed Methods Approaches, 4th ed.; Sage: Thousand Oaks, CA, USA, 2013.

41. Gall, M.D.; Gall, J.P.; Borg, W.R. Applying Educational Research, 7th ed.; Pearson: Boston, MA, USA, 2015.

42. Duff, P. Case Study Research in Applied Linguistics; Lawrence Erlbaum: New York, NY, USA, 2008.

43. Stake, R.E. Multiple Case Study Analysis; Guilford: New York, NY, USA, 2006.

44. Sun, P.; Yuan, R. Understanding collaborative language learning in novice-level foreign language classrooms: Perceptions of teachers and students. Interact. Learn. Environ. 2018, 26, 189-205. [CrossRef]

45. Roness, D. Still motivated? The motivation for teaching during the second year in the profession. Teach. Teach. Educ. 2011, 27, 628-638. [CrossRef]

46. Song, H.; Gu, Q.; Zhang, Z. An exploratory study of teachers' subjective wellbeing: Understanding the links between teachers' income satisfaction, altruism, self-efficacy and work satisfaction. Teach. Teach. Theory Pract. 2020, 26, 3-31. [CrossRef]

47. Mayer, D. The changing face of the Australian teaching profession: New generations and new ways of working and learning. Asia Pac. J. Teach. Educ. 2006, 34, 57-71. [CrossRef]

48. Watt, H.M.G.; Richardson, P.W. Motivations, perceptions, and aspirations concerning teaching as a career for different types of beginning teachers. Learn. Instr. 2008, 18, 408-428. [CrossRef]

49. Shaukat, S.; Vishnumolakala, V.R.; Al Bustami, G. The impact of teachers' characteristics on their self-efficacy and job satisfaction: A perspective from teachers engaging students with disabilities. J. Res. Spec. Educ. Needs 2019, 19, 68-76. [CrossRef]

50. Goller, M.; Ursin, J.; Vähäsantanen, K.; Festner, D.; Harteis, C. Finnish and German student teachers' motivations for choosing teaching as a career. The first application of the FIT-Choice scale in Finland. Teach. Teach. Educ. 2019, 85, 235-248. [CrossRef]

51. Kilday, J.E.; Lenser, M.L.; Miller, A.D. Considering students in teachers' self-efficacy: Examination of a scale for student-oriented teaching. Teach. Teach. Educ. 2016, 56, 61-71. [CrossRef]

52. Klassen, R.M.; Tze, V.M.C.; Betts, S.M.; Gordon, K.A. Teacher efficacy research 1998-2009: Signs of progress or unfulfilled promise? Educ. Psychol. Rev. 2011, 23, 21-43. [CrossRef]

53. Betoret, F.D. Stressors, self-efficacy, coping resources, and burnout among secondary school teachers in Spain. Educ. Psychol. 2006, 26, 519-539. [CrossRef] 
54. Fu, W.; Tang, W.; Xue, E.; Li, J.; Shan, C. The mediation effect of self-esteem on job-burnout and self-efficacy of special education teachers in Western China. Int. J. Dev. Disabil. 2019, 1-10. [CrossRef]

55. Hoy, A.W.; Spero, R.B. Changes in teacher efficacy during the early years of teaching: A comparison of four measures. Teach. Teach. Educ. 2005, 21, 343-356. [CrossRef] 